\title{
SITE RESPONSE ACROSS THE LOS ANGELES BASIN FROM AMBIENT NOISE RECORDED BY A HIGH DENSITY ARRAY
}

\author{
R. $\mathrm{Ng}^{1}$ and J. Polet ${ }^{2}$
}

\begin{abstract}
Sedimentary basins, such as the Los Angeles basin, can substantially amplify ground motion and increase its duration. To account for site response and develop better seismic hazard assessment and mitigation, it is essential to determine site characteristics across the basin at a high spatial resolution. We investigate site response within the Los Angeles Basin through the application of the microtremor Horizontal-to-Vertical Spectral Ratio (HVSR) approach on 3-component broadband waveforms from the Los Angeles Syncline Seismic Interferometry Experiment (LASSIE). LASSIE is a dense array of 73 broadband seismometers that were active for one month, transecting the Los Angeles basin at $1 \mathrm{~km}$ spacing from La Puente to a dense cluster in Long Beach. The spectral peak amplitudes and peak frequencies of the HVSR curves both show variation across the LASSIE network, even between stations that are spaced only $1 \mathrm{~km}$ apart, emphasizing the importance of micro-zonation. Our results show an average resonance period at the basin center of 6 to $10 \mathrm{sec}$. Secondary intermittent shorter period peaks are also observed near the basin edge and may be explained using basin edge resonance, the presence of small scale basins, and/or topographic effects based on their location within the array. Amplified shaking from resonance is characterized by long period HVSR peak amplitudes ranging from 2 to 5.5. The HVSR peak frequencies are higher than those predicted by a simple quarter wavelength function using a weighted velocity from 1-D profiles through the Southern California Earthquake Center Community Velocity Model - Harvard, especially near the center of the basin. Possible factors that may contribute to this discrepancy are oversimplifications used in the calculation, errors in the velocity model, resonance due to a more complex interaction between waves and physical complications introduced by the large dimensions of the LA basin.
\end{abstract}

\footnotetext{
${ }^{1}$ Graduate Student, ConocoPhillips School of Geology and Geophysics, University of Oklahoma, Norman, OK 73069 (email: raymond.ng@ou.edu)

${ }^{2}$ Professor, Geological Sciences Department, California State Polytechnic University, Pomona, CA 91768 (email: jpolet@cpp.edu)
}

Ng R, Polet J. Site Response Across The Los Angeles Basin From Ambient Noise Recorded By A High Density Array. Proceedings of the $11^{\text {th }}$ National Conference in Earthquake Engineering, Earthquake Engineering Research Institute, Los Angeles, CA. 2018. 


\title{
Site Response Across The Los Angeles Basin From Ambient Noise Recorded By A High Density Array
}

\author{
R. $\mathrm{Ng}^{1}$ and J. Polet ${ }^{2}$
}

\begin{abstract}
Sedimentary basins, such as the Los Angeles basin, can substantially amplify ground motion and increase its duration. To account for site response and develop better seismic hazard assessment and mitigation, it is essential to determine site characteristics across the basin at a high spatial resolution. We investigate site response within the Los Angeles Basin through the application of the microtremor Horizontal-to-Vertical Spectral Ratio (HVSR) approach on 3-component broadband waveforms from the Los Angeles Syncline Seismic Interferometry Experiment (LASSIE). LASSIE is a dense array of 73 broadband seismometers that were active for one month, transecting the Los Angeles basin at a $1 \mathrm{~km}$ spacing from La Puente to a dense cluster in Long Beach. The spectral peak amplitudes and peak frequencies of the HVSR curves both show variation across the LASSIE network, even between stations that are spaced only $1 \mathrm{~km}$ apart, emphasizing the importance of micro-zonation. Our results show an average resonance period at the basin center of 6 to $10 \mathrm{sec}$. Secondary intermittent shorter period peaks are also observed near the basin edge and may be explained using basin edge resonance, the presence of small scale basins, and/or topographic effects based on their location within the array. Amplified shaking from resonance is characterized by long period HVSR peak amplitudes ranging from 2 to 5.5. The HVSR peak frequencies are higher than those predicted by a simple quarter wavelength function, using a weighted velocity from 1-D profiles through the Southern California Earthquake Center Community Velocity Model - Harvard, especially near the center of the basin. Possible factors that may contribute to this discrepancy are oversimplifications used in the calculation, errors in the velocity model, resonance due to a more complex interaction between waves and physical complications introduced by the large dimensions of the LA basin.
\end{abstract}

\section{Introduction}

Earthquake hazard is an increasing concern in densely populated, high-rise cities built on basins. It has been well documented that basins amplify earthquake ground motion by, for example, [1] [2] and [3]. Resonance and other forms of ground motion amplification due to basin sediments raise many questions regarding areas such as the Los Angeles basin, as investigated by [4], [5], [6], [7] and [8]. Further studies of basin response of the Los Angeles region through studies such as those conducted by [9], [10] and [11] help improve earthquake engineering standards and hazard assessments. Basin resonance and ground motion amplification in basins have been observed in numerous historical events, where significant loss and failure of large structures was observed, such as the well studied 1985 Michoacan earthquake as evidenced by [2], [12] and

\footnotetext{
${ }^{1}$ Graduate Student, ConocoPhillips School of Geology and Geophysics, University of Oklahoma, Norman, OK 73069 (email: raymond.ng@ou.edu)

${ }^{2}$ Professor, Geological Sciences Department, California State Polytechnic University, Pomona, CA 91768 (email: jpolet@cpp.edu)
}

Ng R, Polet J. Site Response Across The Los Angeles Basin From Ambient Noise Recorded By A High Density Array. Proceedings of the $11^{\text {th }}$ National Conference in Earthquake Engineering, Earthquake Engineering Research Institute, Los Angeles, CA. 2018. 


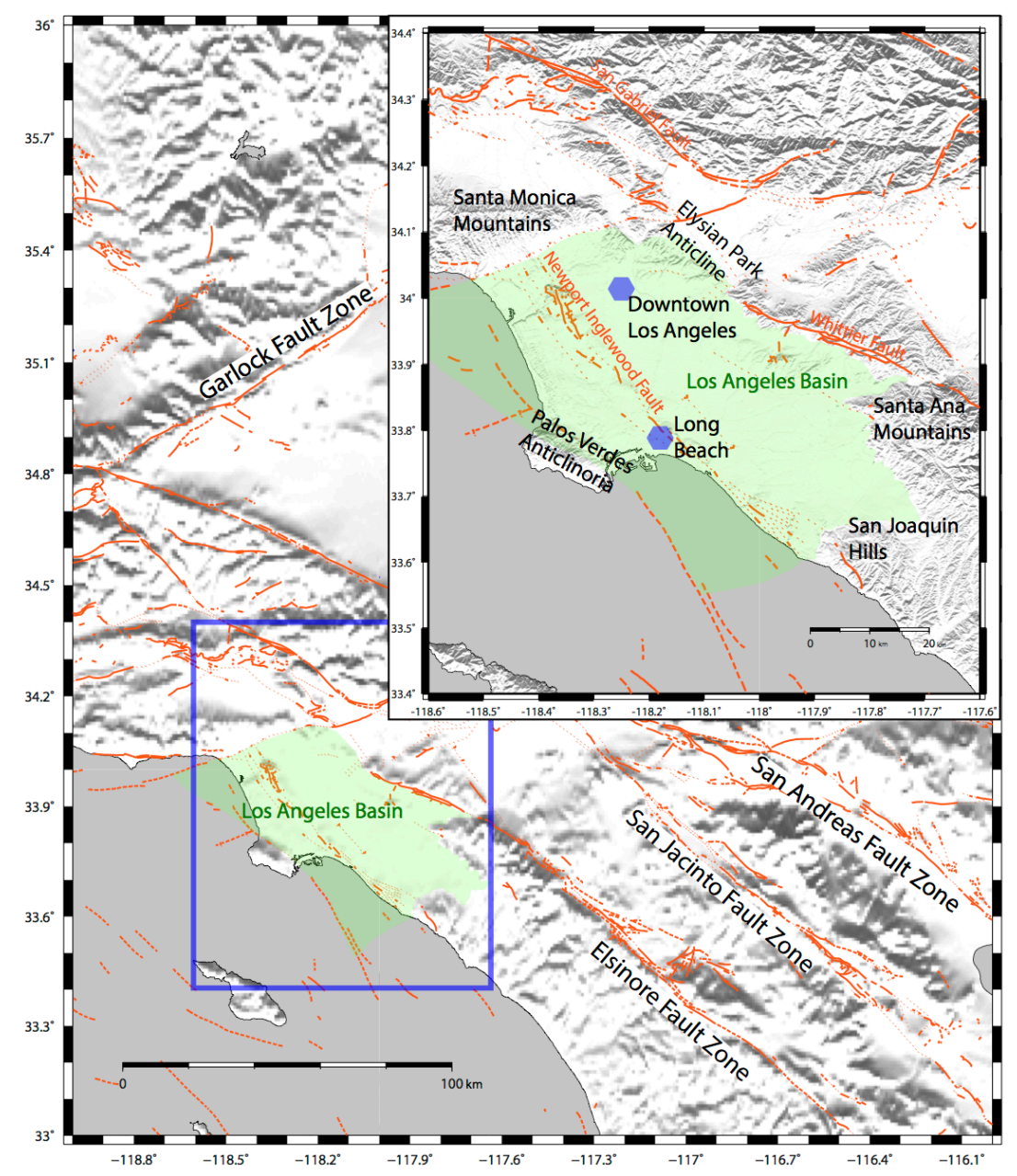

Figure 1. Southern California regional map. Area of inset map is framed with a blue rectangle. Important features are labeled. Faults are shown by orange lines. The locations of downtown Los Angeles and Long Beach are shown by blue polygons.

[13], the 1987 Whittier earthquake by [6] and [14], and the 1994 Northridge earthquake by [6], [15] and [16].

The Los Angeles basin, shown in Fig. 1, slopes gently south towards the coast and is interrupted by a series of low hills from Beverly Hills to Newport, and the Palos Verdes hills in the southernmost section. A very complicated network of faults is scattered throughout the basin. Studies in LA basin stratigraphy, tectonic history, and basin structure are extensive and further understanding of its characteristics is important for application to seismic hazard mitigation. The surface geology of the Los Angeles basin is comprised of sediments of Quaternary and Miocene age, which are underlain primarily by crystalline bedrock and Mesozoic schist [17]. The sediments range in textures from coarse sandstone to shale and fine silt, and layer thickness of units [18] ranges from $21 \mathrm{~m}$ for surficial Holocene deposits, to upper Miocene siliceous shale and sandstones that are $2600 \mathrm{~m}$ thick. Notable petroleum bearing sandstone units are the 


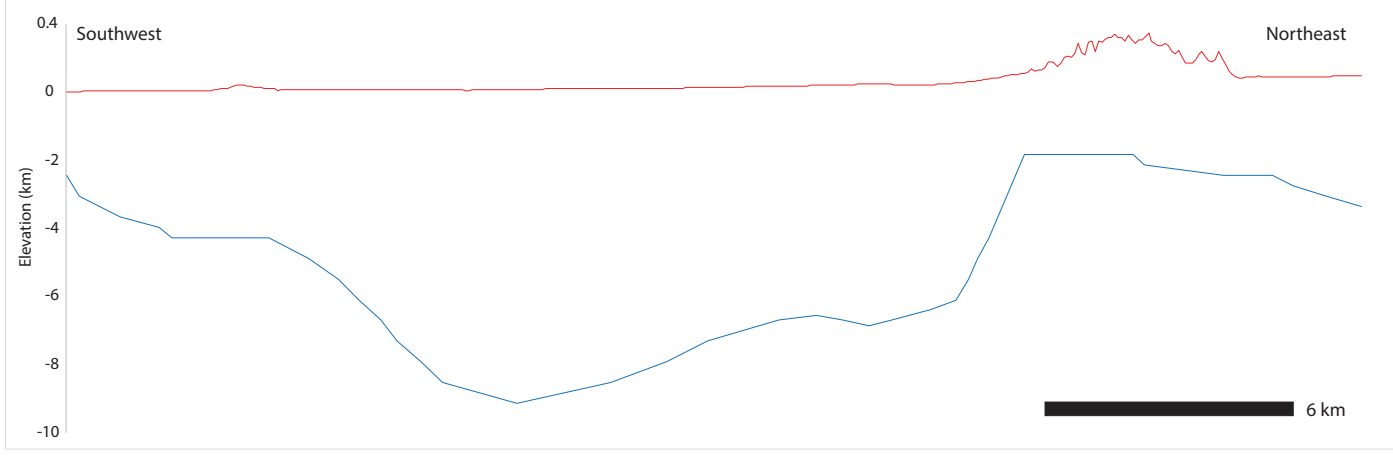

Figure 2. Cross-section of the Los Angeles basin from Long Beach Harbor northeast to West Puente Valley. The blue line shows the basin basement adapted from [18] and the red line corresponds to the surface topography.

Mohnian stage (14 Ma) and the Repetto formation (4.5 Ma). These Miocene and Pliocene units are found at depths of 4,900 $\mathrm{m}-7,300 \mathrm{~m}$ depth in the central basin (Fig. 2). Numerous studies, such as [19], [20] and [21], attempted to constrain the deepest portion of the basin using well data, geological data, seismic reflection, and travel time tomography. All of these models are similar in terms of their large-scale features, with a bowl-shaped structure of the basin and a depth between $8-12 \mathrm{~km}$ at its deepest central portion.

Understanding site effects is key in furthering the knowledge base of ground motion and for the reduction of earthquake-induced damages. Site characteristics are influenced by the type of sediment, the thickness and the location of the sedimentary and bedrock units, and may be characterized by parameters such as the fundamental frequency and ground motion amplification. We apply the microtremor Horizontal to Vertical Spectral Ratio (HVSR) method developed by [22] to data from a temporary broadband array in the Los Angeles basin. This method has been applied in basins in numerous countries worldwide to determine fundamental frequency, amplification, and to derive basin depth as in, for example, [23], [13] and [24]. The HVSR method has been extensively evaluated against other established geophysical methods by [25], [26] and [27], and others.

The ambient noise data used was recorded by 73 broadband seismometers installed as the Los Angeles Syncline Seismic Interferometry Experiment (LASSIE), a collaborative experiment by stakeholders from academia: California Institute of Technology (Caltech), University of California, Los Angeles (UCLA), and California State Polytechnic University, Pomona (Cal Poly Pomona), a federal agency: the United States Geological Survey (USGS), and industry: NodalSeismic, Signal Hill Petroleum, and California Resources Corporation. There are two primary components to the LASSIE network. One component of the LASSIE array is the LA basin transect from Long Beach northeastward towards the City of Industry, north of the Puente Hills at an approximate station spacing of $1 \mathrm{~km}$. This LA basin transect is approximately orthogonal to the horizontal major axis of the basin. The second component of the array is the Long Beach cluster of 29 seismometers over an area of $50 \mathrm{~km}^{2}$. We also include results from several permanent Southern California Seismic Network stations located in the LA basin. 


\section{Measurements and Interpretation}

\section{Measurements}

We use the Geopsy software [28] to determine Horizontal/Vertical Spectral Ratio (HVSR) curves for each station from ambient noise data recorded on three-component waveform data. We analyze the results in accordance with the Site Effects Assessment Using Ambient Excitations (SESAME) guidelines for implementing the HVSR approach [29], which have three conditions for HVSR curve reliability and five criteria for identification of a peak frequency, $\mathrm{f}_{0}$, as a clear peak. An example of a spectral ratio curve for station N106 is shown in Fig. 3. [29] and [30] compared the ambient noise HVSR results with those from earthquake based HVSR analysis and these results were further verified in [27]. A strong linear relationship was demonstrated between the spectral peak frequency determined through ambient noise HVSR and those determined through Standard Spectral Ratio (SPR) measurements from earthquake data. We will therefore refer to the peak frequency measured from the HVSR graph as the site fundamental or resonance frequency. In these same studies, the HVSR peak amplitude was shown to provide a lower bound for site amplification.

Data from 70 stations produced reliable curves; from those reliable curves, we measured 127 peaks. 94 of the 127 measured peaks may be classified as clear peaks according to the SESAME criteria. Our analysis produced a wide variety of HVSR graphs: some spectral ratio curves show multiple peaks occurring at a range of frequencies, some graphs show no peaks or simple clear single peaks. For three stations we could not retrieve data due to hardware issues or

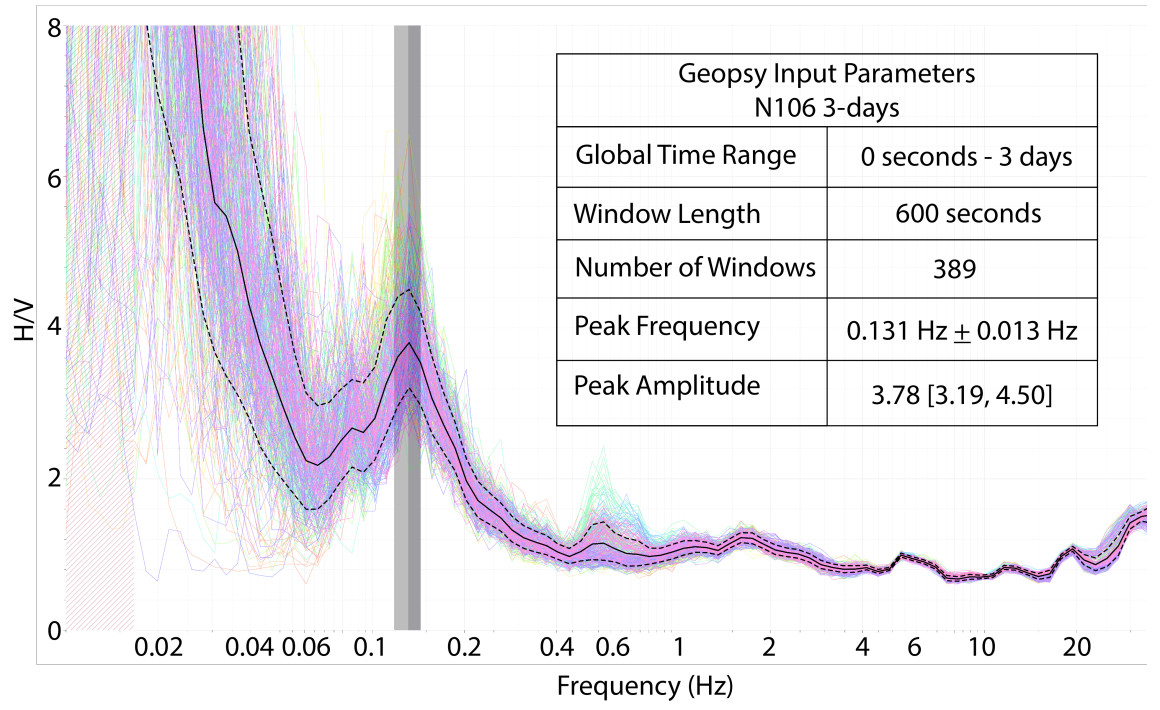

Figure 3. Spectral ratio curve of LASSIE site N106. Each line represents a spectral ratio curve computed for one time window. The solid line shows the geometrical average of all the individual curves. The dashed lines indicate the standard deviation of the amplitude of the average curve. The peak frequency, $\mathrm{f}_{0}$, is surrounded by grey vertical bars that show its standard deviation. 


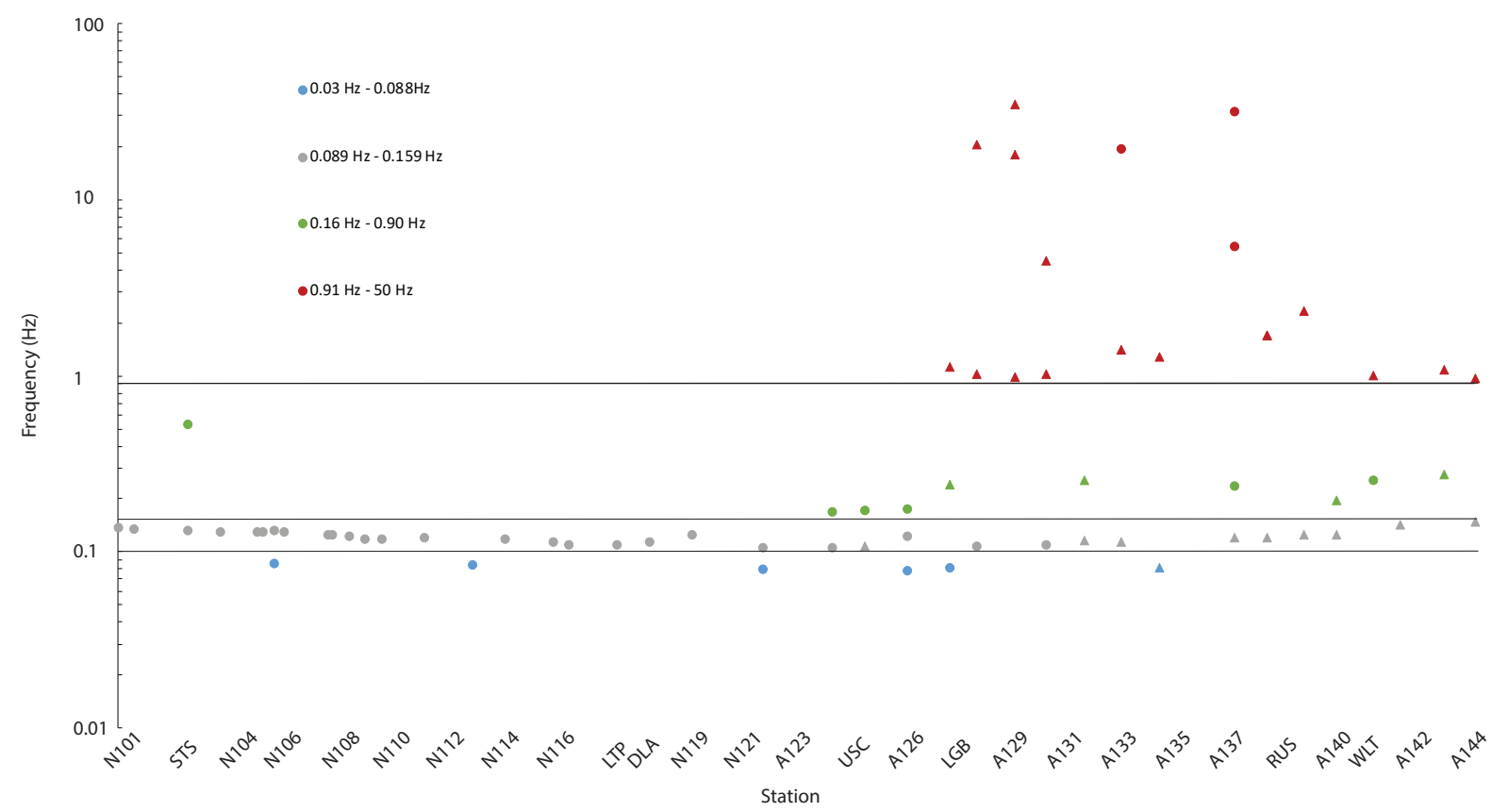

Figure 4. Distribution of LA basin transect peak frequencies. Colors show classification of different frequency groups; circles indicate clear peaks, and triangles are peaks that are not classified as clear. Lines separate frequency groups.

equipment malfunction. However, we still have good spatial coverage of the entire LASSIE experiment. We document 94 clear peaks, as well as 33 peaks that failed two or more of the clear peak criteria. These criteria were developed for single station analysis. Since our network consists of very closely spaced stations, we consider that there is still valuable information contained in peaks that may fail two or more criteria, yet are consistently observed over a significant lateral extent along the network.

\section{Results for Peak Frequencies and Amplitudes}

We observe several coherent sets of spectral ratio peaks, with one group of peaks that could most easily be tracked along the entire network in the frequency range of $0.085 \mathrm{~Hz}-0.159 \mathrm{~Hz}$. We show our reliable curve and clear peak results in Fig. 4, which groups the results in the frequencies ranges of $0.003 \mathrm{~Hz}<\mathrm{f}_{0}<0.088 \mathrm{~Hz}, 0.089 \mathrm{~Hz}<\mathrm{f}_{0}<0.159 \mathrm{~Hz}, 0.160 \mathrm{~Hz}<\mathrm{f}_{0}<0.900 \mathrm{~Hz}$, and $0.900 \mathrm{~Hz}<\mathrm{f}_{0}$. The spectral peak amplitudes and peak frequencies both show variation across the LASSIE network, even between stations that are spaced less than $1000 \mathrm{~m}$ apart, suggesting that the site response in this area varies on a very small scale, and emphasizing the importance of micro-zonation. We observe a dominant, laterally continuous, peak frequency of approximately $0.10 \mathrm{~Hz}-0.15 \mathrm{~Hz}$ across the Los Angeles basin, which we interpret as the primary resonance frequency. This resonance frequency is potentially devastating for buildings approximately 200 $\mathrm{m}-300 \mathrm{~m}$ tall, which have resonance frequencies that fall in that same range. Our measurements are consistent with the work of [7] who used a 3D velocity model of southern California to calculate a theoretical resonance frequency of the LA basin at 10 seconds. Measurements in this frequency range are from 36 of the 44 stations on the LA basin transect. Maps of the variations in spectral peak frequencies and peak amplitudes within and outside of the LA basin are shown 
for all four groups of peaks in Fig. 5. The basin transect is shown by the diagonal line of LASSIE stations from the southwest edge of the basin towards the northeast basin edge.

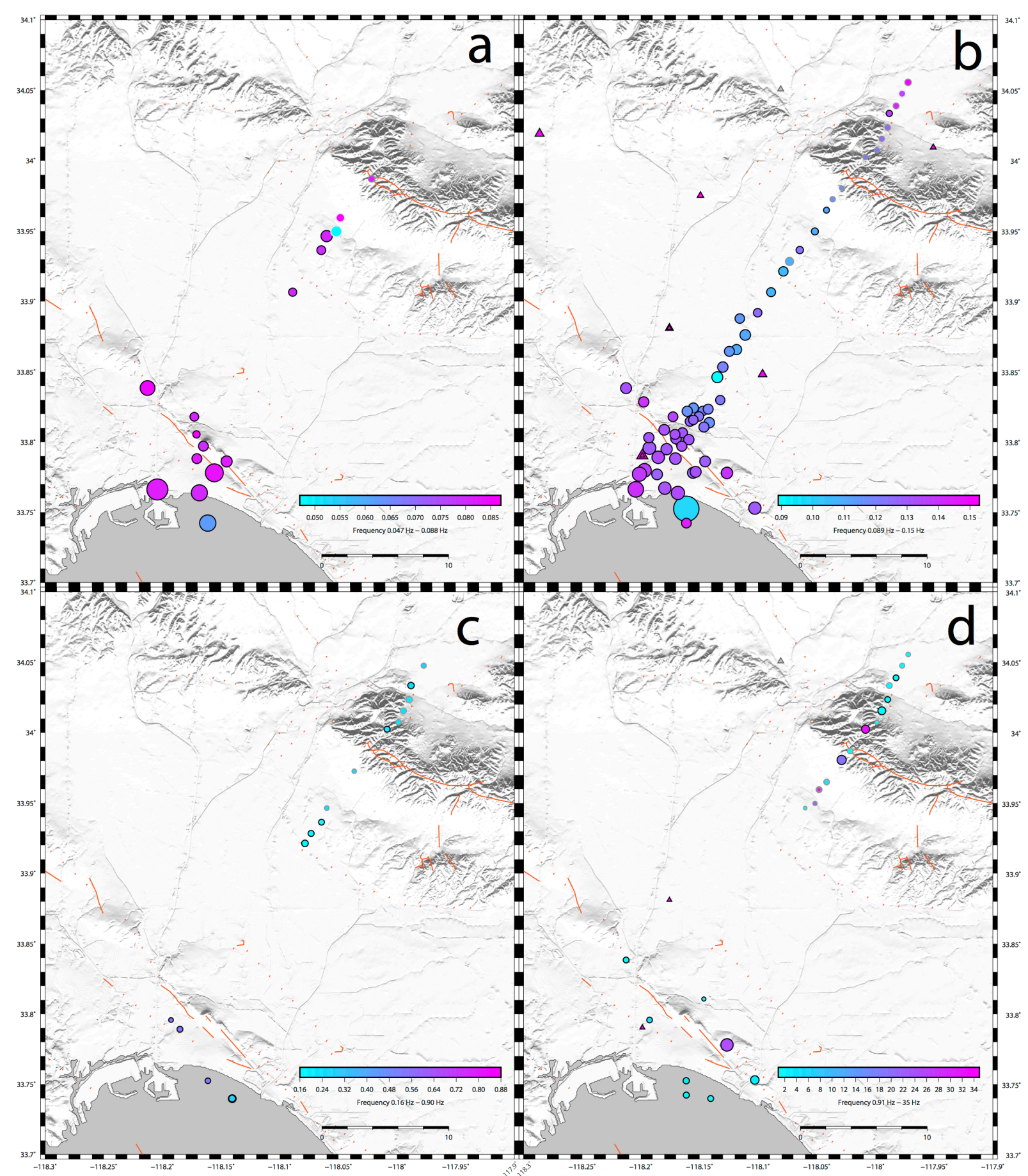

Figure 5. Maps of peak HVSR frequencies, shown by color, and their amplitudes, indicated by the size of the circle. Black outlines indicate clear peaks and gray outlines unclear peaks. Orange lines show faults. Scale bar in units of $\mathrm{km}$. Peak frequencies in the range of: (a) $0.003 \mathrm{~Hz}$ to $0.088 \mathrm{~Hz}$; (b) $0.089 \mathrm{~Hz}$ to $0.159 \mathrm{~Hz}$; (c) $0.160 \mathrm{~Hz}$ to 0.900 $\mathrm{Hz}$ and (d) higher than $0.900 \mathrm{~Hz}$. 


\section{Interpretation of Amplitudes of the Peaks}

The LASSIE network was deployed on Quaternary alluvium and Tertiary sedimentary rock. The measured amplitudes from the $0.085 \mathrm{~Hz}-0.159 \mathrm{~Hz}$ frequency range show good correlation with the Tertiary sedimentary rock along the northeastern boundary of the LA basin (see Fig. 5(b)). We observe a lower spectral peak amplitude, between 1.7 -3, over and near the Tertiary rock, compared to the average peak amplitude of 3.5-4 in the center of the basin. However, the variation in peak amplitude within the basin is counterintuitive, since commonly a thicker sedimentary layer is associated with higher amplification. Higher amplification was for example observed in the deepest part of the Mexico City basin by [13]. However, given the depth of the LA basin, shear wave velocity gradients with depth due to compression of sediments, and layering within the basin itself in general, are likely to have a significant effect.

\section{Comparison of Peak Frequencies with Predictions}

HVSR spectral peaks are commonly associated with a strong acoustic impedance contrast between subsurface layers, and high peaks have been shown in numerous other basin studies (e.g., [31] and [32]) to be related to the sediment-basement contact. We calculate a simple forward prediction for a theoretical resonance frequency for the LASSIE array, using the quarterwavelength function.

$$
\mathrm{f}_{0}=\mathrm{V}_{\mathrm{S}} / 4 \mathrm{~h}
$$

Eq. 1 was used to calculate a fundamental frequency, $\mathrm{f}_{0}$, given an average $\mathrm{S}$-wave velocity of the soil structure, $\mathrm{V}_{\mathrm{S}}$, and a depth to the bottom of the basin, denoted by h. We use the Southern California Earthquake Center (SCEC) Community Velocity Model, Harvard (CVM-H) by [33] in our calculations. We determine the basin depth from this model by analyzing a 1-D velocity profile at the site of each station to identify the jump in shear wave velocity that may be interpreted as the transition from soft basin sediments to bedrock. We calculate a weighted average velocity down to this basin depth and use Eq. 1 to predict a resonance frequency. The HVSR peak frequency results from LASSIE are at a relatively higher frequency than the predictions near the center of the basin as shown in Fig. 6. At the edge of the basin, the difference between the predictions and measurements is less pronounced.

The differences between the HVSR measurements and values predicted from the CVM could be due to several different factors (or a combination of these factors): the velocity model contains velocities that are too low in the center of the basin, the basin is too deep in the CVM model, the assumption of a simple two-layer model (commonly used in other HVSR basin studies) is too severe a simplification for a deep basin such as the LA basin, and therefore the method used in the calculation of the predicted peak frequency is not appropriate, or in the case of a large and deep basin as the LA basin, the resonance frequency is not determined by an Swave bouncing up and down in this basin, but in fact may be the result of a different type of wave or a combination of different waves. It is however important to keep in mind that the HVSR results themselves are measurements of the actual peak frequencies and resonances of the LA basin, independent of any model. 


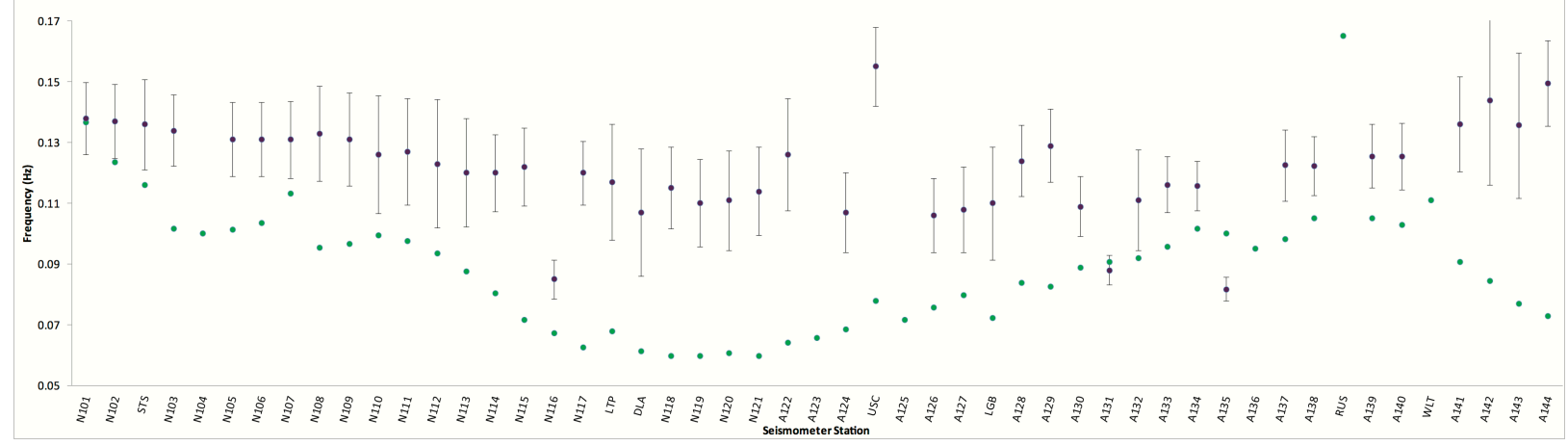

Figure 6. Spectral ratio peak frequencies shown as blue circles with standard deviation, with predicted resonance frequencies from CVM-H shown as green circles.

\section{Interpretation of Secondary Intermittent Spectral Peaks}

For some stations, we observe secondary peaks at lower and/or higher frequencies (see Fig. 5). Based on their location on the edge of the basin and in areas with topographic highs such as ridges, hills and mountains, the secondary intermittent peaks above $0.10 \mathrm{~Hz}$ may be explained by possible basin edge resonance, small-scale basins, and/or resonance due to topography, as described by [34], [35] and [36]. Intermittent low frequency peaks below $0.10 \mathrm{~Hz}$ may be attributed to internal layering within the LA basin. The $2.4 \mathrm{~Hz}$ resonance frequency in Whittier observed by [14] and attributed to basin edge resonance, agrees with a HVSR secondary peak that we measure in that area.

\section{Conclusions}

To study the variation of site effects on a small scale across the Los Angeles basin we collected ambient noise data from 73 broadband seismometers with a seismometer spacing of $1 \mathrm{~km}$ to carry out a spectral ratio analysis. We extract spectral peak frequencies and their amplitudes from spectral ratio curves and interpret these measurements as resonance frequencies and a lower limit for ground motion amplification. The spectral peak amplitudes and peak frequencies both show significant variation across the network, even between stations that are spaced less than $1000 \mathrm{~m}$ apart, suggesting that the site response in this area varies on a very small scale and emphasizing the importance of micro-zonation.

We identify a primary spectral peak frequency inside the LA basin that is laterally coherent, with slight variations in frequency from $0.10 \mathrm{~Hz}$ to $0.15 \mathrm{~Hz}$, which we interpret to be the primary resonance frequency of the LA basin. Based on the amplitudes of these peaks, we observe the potential for ground motion amplification within the basin compared to locations outside of the basin by a factor of up to 5. The spectral amplitudes of these peaks within the basin do not follow a trend based on sediment thickness.

We calculate the predicted resonance frequency for the SCEC CVM-H model using the quarter wavelength approach, and find that these frequencies are consistently lower than our measurements. Possible explanations for the discrepancy between our measurements and the predicted resonance frequencies include: the presence of a significantly higher shear wave 
velocity within the basin than included in the model, an overestimation of the basin depth in the model, an oversimplification of the method used to calculate predicted values and the assumption that the resonance is due to a vertically inclined single mode shear wave.

We also observe several additional sets of peaks at higher frequencies, most near the basin edge or near topographic features. Based on the location of these measurements of intermittent secondary peaks, they may be explained by basin edge resonance, the presence of small-scale basins, and/or topographic effects.

\section{Acknowledgements}

We would like to thank Robert Clayton (Caltech), Mitchell Barklage, Bill Erickson and Dan Hollis (NodalSeismic), Elizabeth Cochran (USGS, Pasadena), Paul Davis (UCLA), Catherine Cox and Michael Padgett (Signal Hill Petroleum) for their contributions to the LASSIE project.

\section{References}

1. Frankel AD, Carver DL, Williams RA. Nonlinear and linear site response and basin effects in Seattle for the M 6.8 Nisqually, Washington, earthquake. Bulletin of the Seismological Society of America 2002; 92 (6): 2090 2109.

2. Hall JF, Beck JL. Structural damage in Mexico City. Geophysical Research Letters 1986; 13 (6): 589 - 592.

3. Kagami H, Okada S, Shiono K, Daravinski MO, Daeavinski M, Mal A. Observation of 1-to 5-second microtremors and their application to earthquake engineering. Part III. A two-dimensional study of site effects in the San Fernando Valley. Bulletin of the Seismological Society of America 1986; 76 (6): 1801 - 1812.

4. Rogers AM, Tinsley JC, Hays WW, King KW. Evaluation of the relation between near-surface geological units and ground response in the vicinity of Long Beach, California. Bulletin of the Seismological Society of America 1979; 69 (5): 1603 - 1622.

5. Brady A, Etheredge E, Porcella R. The Whittier Narrows, California earthquake of October 1, 1987-Preliminary assessment of strong ground motion records. Earthquake Spectra 1988; 4 (1): 55 - 74.

6. Hruby CE, Beresnev IA. Empirical corrections for Basin effects in stochastic ground-motion prediction, based on the Los Angeles basin analysis. Bulletin of the Seismological Society of America 2003; 93 (4): 1679 - 1690.

7. Wald DJ, Graves RW. The Seismic Response of the Los Angeles Basin, California. Bulletin of the Seismological Society of America 1998; 88 (2): 337 - 356.

8. Olsen KB. Site amplification in the Los Angeles basin from three-dimensional modeling of ground motion. Bulletin of the Seismological Society of America 2000; 90 (6B): 6 - 77.

9. Louie JN. Shear-wave velocity map for California. US Geological Survey Technical Report, 07HQGR0029 2007.

10. Mahdyiar M. Are NEHRP and Earthquake-based Site Effects in Greater Los Angeles Compatible? Seismological Research Letters 2002; 73 (1), 39 - 45.

11. Mihalic S, Maja O, Krkac M. Seismic microzonation: A review of principles and practice. Geofizika $2011 ; 28$ (1): 5 - 20 .

12. Flores-Estrella H, Yussim S, Lomnitz C. Seismic response of the Mexico City Basin: A review of twenty years of research. Natural Hazards 2007; 40 (2): 357 - 372.

13. Lermo J, Chavez - Garcia, FJ. Are microtremors useful in site response evaluation? Bulletin of the Seismological Society of America 1994; 84 (5): 1350 - 1364.

14. Kawase H, Aki K. Topography effect at the critical SV-wave incidence Possible explanation of damage pattern by the Whittier Narrows, California, earthquake of 1 October 1987. Bulletin of the Seismological Society of America 1990; 80 (1): 1 - 22. 
15. Hartzell S, Leeds A, Frankel A, Michael J. Site response for urban Los Angeles using aftershocks of the Northridge earthquake. Bulletin of the Seismological Society of America 1996; 86 (1B): 168 - 192.

16. Graves RW. Preliminary analysis of long-period basin response in the Los Angeles region from the 1994 Northridge earthquake. Geophysical Research Letters 1995; 22 (2): 101 - 104.

17. Jennings CW, Strand R, Rogers T, Boylaw R. Geologic map of California. Division of Mines \& Geology 1977.

18. Yerkes R, McCulloh T, Schoellhamer J, Vedder J. Geology of the Los Angeles Basin - Introduction. Geological Survey Professional Papers. (US);(United States) 1965; 420-A.

19. McCulloh TH. Gravity variations and the geology of the Los Angeles basin in California. US Geological Survey Professional Paper 1960; 400-B : 320 - 325.

20. Hauksson E, Haase JS. (1997). Three-dimensional VP and VP/VS velocity models of the Los Angeles basin and central Transverse Ranges, California. Journal of Geophysical Research 1997; 102 (B3), 5423 - 5453.

21. Magistrale H, McLaughlin K, Day S. A geology-based 3D velocity model of the Los Angeles basin sediments. Bulletin of the Seismological Society of America 1996; 86 (4): 1161 - 1166.

22. Nakamura Y. A method for dynamic characteristics estimation of subsurface using microtremor on the ground surface. Railway Technical Research Institute, Quarterly Reports 1989; 30 (1).

23. Lachet $\mathrm{C}$, Bard PY. Numerical and Theoretical Investigations on the Possibilities and Limitations of Nakamura's Technique. Journal of the Physical Earth 1994; 42: 377 - 397.

24. Uebayashi H, Kawabe H, Kamae K, Horike M. Behavior of Microtremor H / V Spectrum and Phase Velocity on the Basin Peripheral and Inversion for Determining Basin Structure. The 14th World Conference on Earthquake Engineering 2008; 2 - 37.

25. Zhao B, Horike M, Yoshihiro T. Analytical study on reliability of seismic site-specific characteristics estimated from microtremor measurements. Proceeding of the 12th World Conference on Earthquake Engineering 2000; $1522-1530$.

26. Mucciarelli M, Gallipoli MR, Arcieri M. The stability of the horizontal-to-vertical spectral ratio of triggered noise and earthquake recordings. Bulletin of the Seismological Society of America 2003; 93 (3): 1407 - 1413.

27. Bard PY, Jongmans D, Ohrnberger M, Wathelet M. Site effects assessment using ambient excitations (SESAME). European Commission, Final Report (Project No. EVG1-CT-2000-00026 SESAME) 2005.

28. Wathelet M. Geopsy project. Software, LGIT, Grenoble, Fr. 2011.

29. SESAME WP12. Guidelines for the implementation of the H/V spectral ratio technique on ambient vibrations. Measurements, processing and interpretation. SESAME European research project. European Commission. Project No. EVG1-CT-2000-00026 SESAME, D23.12 2004.

30. Bard PY, SESAME Participants. The SESAME project: an overview and main results. Proceedings of the 13th World Conference on Earthquake Engineering, Vancouver 2004.

31. Seht MIV, Wohlenberg J. Microtremor Measurements Used to Map Thickness of Soft Sediments. Bulletin of the Seismological Society of America 199989 (1): 250 - 259.

32. Parolai S, Bormann P, Milkereit C. New relationships between Vs, thickness of sediments, and resonance frequency calculated by the $\mathrm{H} / \mathrm{V}$ ratio of seismic noise for the cologne area (Germany). Bulletin of the Seismological Society of America 2002; 92 (6), 2521 - 2527.

33. Plesch A, Tape C, Shaw J, USR Working Group and Others. CVMH 6.0: Inversion integration, the San Joaquin Valley and other advances in the community velocity model. 2009 Southern California Earthquake Center Annual Meeting, Proceedings and Abstracts 2009; 19: 260 - 261.

34. Spudich P, Hellweg M, Lee WHK. Directional topographic site response at Tarzana observed in aftershocks of the 1994 Northridge, California, earthquake: implications for mainshock motions. Bulletin of the Seismological Society of America 1996; 86 (1B): 193 - 208.

35. Hough SE, Yong A, Altidor JR, Anglade D, Given D, Mildor SL. Site characterization and site response in Port-Au-Prince, Haiti. Earthquake Spectra 2011; 27 (S1): 137 - 155.

36. Assimaki D, Jeong S. Ground-motion observations at hotel Montana during the M 7.02010 Haiti earthquake: Topography or soil amplification? Bulletin of the Seismological Society of America 2013; 103 (5): 2577 - 2590. 